\title{
The relationship between osteoarthritis and osteoporosis in the general population: The Chingford Study
}

\author{
Deborah J Hart, Indeera Mootoosamy, David V Doyle, Tim D Spector
}

\begin{abstract}
Objective-A total of 979 women from the Chingford general population survey were studied to examine the hypothesis that osteoarthritis (OA) and osteoporosis are inversely related.

Methods-All women had radiographs of the hands and knees. A total of 579 also had AP radiographs of the lumbar spine which were graded for the presence of osteophytes. All women had bone densitometry performed at the lumbar spine (L1-L4) and femoral neck. Mean bone densities (BMD) were compared between those with disease and those with no disease at any other sites. All results were adjusted for age and body mass index (BMI).

Results-All OA groups had significantly higher bone density than controls at the lumbar spine. For distal interphalangeal (DIP) OA $(n=140)$ the difference was $+5 \cdot 8 \%(+3 \cdot 0,+8 \cdot 6)$, for carpometacarpal (CMC) OA $(n=160)+3.0 \%(+0 \cdot 1,+5 \cdot 9)$, for knee OA $(n=118)+7 \cdot 6 \%(+4 \cdot 3,+10 \cdot 9)$, and lumbar spine OA (LSOA) $(n=194)$ $+7 \cdot 8 \%(+6 \cdot 0,+8 \cdot 8)$. Those with generalised OA (GOA $n=22$ ), a combination of knee, DIP and CMC OA had an increase of $+9 \cdot 3$ $(+2 \cdot 0,+16 \cdot 6)$. For the femoral neck BMD was also increased significantly ranging from $+2 \cdot 5 \%$ for the CMC, $+6 \cdot 2 \%$ for the knee and $+6 \cdot 3 \%$ in the lumbar spine $O A$ group. The risk of knee OA for women in the top tertile of BMD was $2 \cdot 13$ (1·15-3.93). Additional adjustment for other confounders such as smoking, alcohol, exercise, HRT, social class and spine osteophytes did not alter the results.

Conclusions-These results suggest that small increases in BMD are present in middle aged women with early radiological $O A$ of the hands, knees and lumbar spine. These data support the hypothesis that the two conditions are inversely related, although the mechanisms remain unclear.
\end{abstract}

(Ann Rheum Dis 1994; 53: 158-162)

Decreased bone mass and osteoarthritis (OA) are both common conditions in elderly women. Early studies suggested that the two rarely coexist clinically. The first study, by Foss and Byers, which looked at this relationship found that OA of the hip is rarely seen together with a fractured neck of the femur. ${ }^{1}$ Dequeker suggested that two very different groups of subjects exist, the lean osteoporotic and the fatter osteoarthritic with increased bone mass, muscle strength and fewer fractures. ${ }^{3}$ Cooper found a dearth of patients who had OA and low bone density (as graded by the Singh index) in a group of 314 men and women undergoing radiography for non-skeletal conditions. ${ }^{4}$ Others, however, have failed to find a relationship. Price found a significant difference in bone mineral density (BMD) when adjusting for age, which disappeared after adjusting for height and weight. $^{6}$ Other studies have also been inconclusive. ${ }^{7}$ Much of the previous studies were based on small numbers with often poorly matched controls, and using relatively crude techniques to detect bone loss. Many subjects had advanced disease and if $\mathrm{OA}$ has been present for some time the resulting immobility is likely to affect bone mass. We therefore chose to examine the relationship between bone density and early OA of the hand, knee and spine using a middle-aged general population sample and high precision dual $x$ ray absorbtiometry of the spine and femoral neck (FN).

\section{Methods}

From an age/sex register of a large practice of over 11000 patients in Chingford, outer London, all 1353 women in the age range 45-64 years (mean 54.2) were invited to participate in a study assessing musculoskeletal disease in the population. Women from this general practice are similar to the UK general population in terms of weight $(65 \mathrm{~kg}$ in the UK, $67 \mathrm{~kg}$ in Chingford), height $(161 \mathrm{~cm} v 162$ $\mathrm{cm})$ and BMI $(25.4 v 25.6 \mathrm{~kg} / \mathrm{m}){ }^{8}$ In terms of smoking habits $35 \%$ of women in England and Wales are current smokers compared with $23 \%$ in the Chingford population. ${ }^{9}$ Larger studies of other population groups have shown similar rates of hysterectomy $25 \% v 23 \% .^{10}$ All the women lived within five miles of the general practice and $98 \%$ of the women were white. The area is predominantly middle class but with a range of all social groups. A socioeconomic profile was performed using the Acorn classification system which is based on each subject's postcode and residence (CACI

St Thomas's Hospital,
London SE1 7EH,
United Kingdom
Department of
Rheumatology
D J Hart
T D Spector
Whipps Cross
Hospital,
London E11,
United Kingdom
Department of
Radiology
I Mootoosamy
Department of
Rheumatology
D V Doyle
Correspondence to:
Dr T D Spector,
Department of
Rheumatology,
St Thomas's Hospital,
Lambeth Palace Road,
London SE1 7EH,
United Kingdom.
Accepted for publication
13 August 1993


International, London). These codes were linked to one of four socio-economic categories. The majority of the women $(42 \%)$ belonged to group $\mathrm{C} 1$ (mid to lower middle class, white collar workers), $32 \%$ were $\mathrm{A} / \mathrm{B}$, $17 \% \mathrm{C} 2$ and $8 \% \mathrm{D} / \mathrm{E}$.

All women were given a nurse-administered standardised questionnaire. Height was recorded in metres and weight in kilograms. Body mass index (BMI) was calculated as $\mathrm{kg} / \mathrm{m}^{2}$. A detailed questionnaire was completed on the physical demands of occupation, and physical activity undertaken currently and at the age of 30 . Each woman was given an overall physical activity score which was subdivided into tertiles.

OA was classified radiologically using standard AP $x$ rays of the hands and weight bearing knees which were taken at the same time as the examination. Radiographs were scored 'blind' to clinical details according to the method of Kellgren and Lawrence (K \& L) using the Atlas of Standard Radiographs by a single trained observer 'blind' to the clinical or BMD data. ${ }^{11}$ We have found that this method has good reproducibility. ${ }^{12}$ An individual was considered to have radiographic OA (ROA) of the knee and first carpometacarpal joints (CMC) if at least grade $2 \mathrm{~K} \& \mathrm{~L}$ was present on either side, and for the distal interphalangeal joints (DIP) grade $2+$ changes had to be present in two or more joints to be positive. For the purpose of this investigation, generalised osteoarthritis (GOA) was defined as the combination of radiological DIP, CMC and knee OA. For the knee, $x$ rays were also graded for individual features of OA using a standard atlas. ${ }^{13}$ Osteophytes and narrowing in individual compartments were graded visually using a $0-3$ scale with $1+$ being considered positive. Minimum joint space was also assessed using a ruler ( $\mathrm{mm}$ ), and with digital image analysis $(\mathrm{mm}) .{ }^{14}$ Cut-offs of disease positive for these levels were chosen as approximately the 10 th percentile of their distribution in the full population sample. For osteophytes and visual narrowing grade $\geq 1$ was chosen as the 10th percentile, for ruler the measurement was $\leq 2 \mathrm{~mm}$, and for the digital image analysis measurement $\leq 3.6 \mathrm{~mm}$. A $10 \%$ level was chosen as it was similar to the reported levels of radiographic OA (using $\mathrm{K} \& \mathrm{~L}$ grade $2+$ ) in individual knees, in subjects aged 50-70 from different population surveys. ${ }^{15}$

A total of 579 women also had $x$ rays of the thoracic and lumbar spine, and osteoarthritis was graded on a $0-3$ scale for the presence of osteophytes. ( $0=$ none, $1=$ minimal, $2=$ definite, $3=$ severe). Lumbar spine $O A$ (LSOA) was defined as present in those graded $1+.{ }^{16}$

Bone mineral density was taken of L1-L4 spinal region, and femoral neck using dual $x$ ray absorptiometry (DXA) using a Hologic QDR 1000.

\section{Analysis}

Mean BMD for spine and FN were calculated within each joint group. For each site, cases with radiological osteoarthritis (ROA) were compared with controls defined as women who had no radiological evidence of OA of the hand or the knee. Results are presented as the mean percentage difference from controls with $95 \%$ confidence intervals. Potential confounding variables were adjusted for using analysis of covariance in the SPSS PC software package. Adjustment for age, and age and BMI are presented as it is unclear whether BMI acts as a confounder or whether it may be causally related to both osteoporosis and osteoarthritis.

\section{Results}

Of the 1353 women invited to take part in the study, 1003 were examined, six died, 66 had moved away and 278 refused or did not respond. This gave a crude response rate of $74 \%$, adjusted $78 \%$. The mean characteristics and the prevalence of $\mathrm{OA}$ at different sites in the 979 women with bone mineral density measures are given in table 1 . The prevalence of ROA was $14 \cdot 2 \%$ for the DIP, $16 \cdot 3 \%$ for the CMC, $12 \cdot 1 \%$ for the knee, $2 \cdot 2 \%$ for GOA and $33.5 \%$ for LSOA. The prevalence of women with LSOA was: for those affected at the DIP $42 \%$, for the CMC $45 \%$, for the knee $51 \%$, for GOA $64 \%$, and in the 316 controls, $27.5 \%$. These figures were based on the 579 women who had lumbar spine radiographs. LSOA was most prevalent in association with GOA $(64.3 \%)$, and lowest in those with no OA in the hands or knees $(27 \cdot 5 \%)$.

Mean BMD for spine and FN are shown in table 2 by each joint group and the frequencies were normally distributed. These results are presented as age, and age and BMI adjusted values. For spine BMD all positive individuals in each joint group showed an increase in BMD compared with controls for DIP $+5 \cdot 8 \%$ $(+3 \cdot 0,+8 \cdot 6), \mathrm{CMC}+3 \cdot 0 \%(+0 \cdot 1,+5 \cdot 9)$, knee $+7 \cdot 6 \%(+4 \cdot 3,+10 \cdot 9)$, GOA $+9 \cdot 3 \%(+2 \cdot 0$, $+16 \cdot 6)$ and LSOA $+7 \cdot 8 \%(+6 \cdot 0,+8 \cdot 8)$. For BMD FN all sites had higher BMD in affected individuals, although this was only significantly raised in $\mathrm{CMC}+2 \cdot 5 \%(+0 \cdot 3,+4 \cdot 7)$, knee $+6 \cdot 2 \%(+3 \cdot 5,+8 \cdot 9)$ and LSOA $+6 \cdot 3 \%(+3 \cdot 7$, $+8 \cdot 9)$.

In addition to age and BMI adjustment, the data were also adjusted for the presence of LSOA. No major differences occurred with bone density in the OA groups remaining

Table 1 Characteristics and frequency of radiological $O A$ in 979 women in whom $x$ rays and bone densitometry of the spine were available

\begin{tabular}{llc}
\hline & Mean & (SD) \\
\hline Age (years) & $54 \cdot 2$ & $(6 \cdot 03)$ \\
Weight (kg) & $66 \cdot 9$ & $(11 \cdot 84)$ \\
BMI Kg/m ${ }^{2}$ (units) & $25 \cdot 6$ & $(4 \cdot 30)$ \\
Age menopause (years) & $47 \cdot 6$ & $(5 \cdot 26)$ \\
\hline & $N$ & $\%$ \\
\hline Ever smoked & 463 & $(47 \cdot 3)$ \\
Ever HRT & 238 & $(24 \cdot 3)$ \\
Distal interphalangeal OA & 140 & $(14 \cdot 3)$ \\
Carpo-metacarpal OA & 160 & $(16 \cdot 3)$ \\
Knee OA & 118 & $(12 \cdot 1)$ \\
Generalised OA & 22 & $(2 \cdot 25)$ \\
Lumbar spine OA & $194 \dagger$ & $(33 \cdot 5)$ \\
\hline
\end{tabular}

tBased on 579 lumbar spine $x$ rays. 
Table 2 Mean BMD $\left(\mathrm{g} / \mathrm{cm}^{2}\right)(S D)$ and \% difference with $95 \%$ CI for spine and femoral neck by joint site adjusting for age and age and $B M I$

\begin{tabular}{|c|c|c|c|c|c|c|c|}
\hline \multirow{2}{*}{\multicolumn{2}{|c|}{ foint }} & \multirow[b]{2}{*}{ No } & \multicolumn{3}{|l|}{ Adjusted for age } & \multicolumn{2}{|c|}{ Adjusted for age and BMI } \\
\hline & & & Lumbar spine & No & Femoral neck & Lumbar spine & Femoral neck \\
\hline & 0 & 604 & $0.96(0 \cdot 16)$ & 565 & $0.76(0 \cdot 13)$ & 0.97 & $0 \cdot 76$ \\
\hline DIP & 1 & 137 & $1 \cdot 01(0 \cdot 15)$ & 117 & $0.77(0 \cdot 10)$ & $1 \cdot 03$ & $0 \cdot 77$ \\
\hline & & & $+5 \cdot 2 \%(+2 \cdot 2,+8 \cdot 2)$ & & $+1 \cdot 3 \%(-0 \cdot 7,+3 \cdot 3)$ & $+5 \cdot 8(+3 \cdot 0,+8 \cdot 6)$ & $+1 \cdot 3 \%(-0.9,+3 \cdot 5)$ \\
\hline & 0 & 604 & $0.96(0.16)$ & 565 & $0.77(0.13)$ & $0 \cdot 96$ & 0.77 \\
\hline $\mathrm{CMC}$ & 1 & 158 & $\begin{array}{l}1 \cdot 01(0 \cdot 17) \\
+4 \cdot 2 \%(+1 \cdot 2,+7 \cdot 2)\end{array}$ & 135 & $\begin{array}{l}0.77(0 \cdot 12) \\
+0 \%(-0 \cdot 2,+2 \cdot 0)\end{array}$ & $\begin{aligned} & 1 \cdot 00 \\
+ & 3 \cdot 0(+0 \cdot 1,+5.9)\end{aligned}$ & $\begin{array}{l}0.79 \\
+2 \cdot 5 \%(+0 \cdot 3,+4 \cdot 7)\end{array}$ \\
\hline & 0 & 604 & $0.97(0.16)$ & 565 & $0.77(0.13)$ & 0.97 & 0.76 \\
\hline KNEE & 1 & 117 & $\begin{array}{l}1 \cdot 00(0 \cdot 17) \\
+5 \cdot 1 \%(+2 \cdot 1,+8 \cdot 1)\end{array}$ & 100 & $\begin{array}{l}0 \cdot 80(0 \cdot 13) \\
+2 \cdot 6 \%(-0 \cdot 4,+5 \cdot 6)\end{array}$ & $\begin{aligned} & 1 \cdot 05 \\
+ & 7 \cdot 6(+4 \cdot 3,+10 \cdot 9)\end{aligned}$ & $\begin{array}{l}0 \cdot 81 \\
+6 \cdot 2 \%(+3 \cdot 5,+8 \cdot 9)\end{array}$ \\
\hline & 0 & 604 & $0.98(0.16)$ & 565 & $0.77(0.13)$ & 0.98 & 0.77 \\
\hline GOA & 1 & 21 & $\begin{aligned} & 1 \cdot 03(0 \cdot 17) \\
+ & 5 \cdot 1 \%(-1 \cdot 9,+12 \cdot 1)\end{aligned}$ & 15 & $\begin{array}{r}0.80(0 \cdot 13) \\
+3.9 \%(-2 \cdot 1,+9.9)\end{array}$ & $\begin{array}{l}1 \cdot 08 \\
+9 \cdot 3 \%(+2 \cdot 0,+16 \cdot 6)\end{array}$ & $\begin{aligned} & 0.81 \\
+ & 4.9 \%(-1 \cdot 4,+11 \cdot 2)\end{aligned}$ \\
\hline & 0 & 372 & $0.96(0 \cdot 16)$ & 330 & $0.75(0.13)$ & 0.94 & 0.74 \\
\hline SPINE OA & & 188 & $\begin{aligned} & 1 \cdot 01(0 \cdot 16) \\
+ & 5 \cdot 2 \%(+2 \cdot 2,+8 \cdot 2)\end{aligned}$ & 172 & $\begin{array}{l}0 \cdot 79(0 \cdot 14) \\
+5 \cdot 3 \%(+2 \cdot 3,+8 \cdot 3)\end{array}$ & $\begin{aligned} & 1 \cdot 02 \\
+ & 7 \cdot 8(+6 \cdot 0,+8 \cdot 8)\end{aligned}$ & $\begin{array}{l}0 \cdot 79 \\
+6 \cdot 3 \%(+3 \cdot 7,+8 \cdot 9)\end{array}$ \\
\hline
\end{tabular}

higher at each joint site (that is, DIP $+5 \%$, CMC $+4 \%$, knee $+8.6 \%$ and GOA $+5 \cdot 8 \%$ ). Additional adjustment for smoking status, HRT use, age of menopause, alcohol, social class and physical activity made no important changes in the means or significance of the results (data not shown). Analysis was also repeated using weight and height independently and no difference was seen in the results.

Using only symptomatic $x$ ray positive cases as the definition of disease did not alter the differences in BMD (for example, in symptomatic OA of the knee), the difference in spine BMD was $+7 \cdot 3 \%(+6 \cdot 8,+7 \cdot 7)$.

Table 3 shows the analysis repeated using a different definition of knee OA based on individual radiographic features. In individuals with reduced joint space defined visually on a 0-3 scale or automatically using a ruler or computer image, without osteophytes a modest increase in LSBMD was seen of between $2-4 \%$ in the age and BMI adjusted results. Only 31 individuals had knee osteophytes alone, and they had a non-significantly increased spine

Table 3 Mean BMD (g/cm ${ }^{2}$ ) (SD) for: (a) spine and (b) femoral neck and \% difference from controls by joint space narrowing only and osteophyte only in the knee adjusted for age and age and $B M I$

A

\begin{tabular}{|c|c|c|c|c|}
\hline & & No & Age adjusted & Age and BMI adjusted \\
\hline $\begin{array}{l}\text { Osteophyte only } \\
\quad(0-3) \\
\geq 1\end{array}$ & $\begin{array}{l}0 \\
1\end{array}$ & $\begin{array}{r}604 \\
31\end{array}$ & $\begin{array}{l}0.98(0.16) \\
1.06(0.16) \\
+7.5 \%(+1.5,+13.5)\end{array}$ & $\begin{array}{l}0.98(0.16) \\
1.03(0.17) \\
+4.9 \%(-1.1,+10.9)\end{array}$ \\
\hline $\begin{array}{l}\text { Visual narrowing } \\
\text { only }(0-3) \\
\geq 1\end{array}$ & $\begin{array}{l}0 \\
1\end{array}$ & $\begin{array}{r}576 \\
15\end{array}$ & $\begin{array}{l}0.97(0 \cdot 16) \\
1.00(0 \cdot 25) \\
+3.0 \%(-9 \cdot 8,+15 \cdot 8)\end{array}$ & $\begin{array}{l}0.97(0.16) \\
0.99(0.25) \\
+2.0 \%(-10 \cdot 8,+14.8)\end{array}$ \\
\hline $\begin{array}{l}\text { Ruler narrowing } \\
\text { only } \\
\leq 2 \mathrm{~mm}\end{array}$ & $\begin{array}{l}0 \\
1\end{array}$ & $\begin{array}{r}582 \\
21\end{array}$ & $\begin{array}{l}0.97(0 \cdot 16) \\
1.02(0 \cdot 13) \\
+4.9 \%(-1 \cdot 5,+11 \cdot 3)\end{array}$ & $\begin{array}{l}0.97(0.16) \\
1.01(0 \cdot 15) \\
+4.0 \%(-2 \cdot 4,+10 \cdot 4)\end{array}$ \\
\hline $\begin{array}{l}\text { Digital image } \\
\text { Narrowing only } \\
\leq 3.6 \mathrm{~mm}\end{array}$ & $\begin{array}{l}0 \\
1\end{array}$ & $\begin{array}{r}575 \\
40\end{array}$ & $\begin{array}{l}0.98(0 \cdot 16) \\
1.04(0 \cdot 15) \\
+5.8 \%(+1 \cdot 1,+10.5)\end{array}$ & $\begin{array}{l}0.98(0.16) \\
1.02(0.15) \\
+3.9 \%(-0.8,+8 \cdot 6)\end{array}$ \\
\hline \multicolumn{5}{|l|}{ B } \\
\hline & & No & Age adjusted & Age and BMI adjusted \\
\hline $\begin{array}{l}\text { Osteophyte only } \\
\quad(0-3) \\
\geq 1\end{array}$ & $\begin{array}{l}0 \\
1\end{array}$ & $\begin{array}{r}565 \\
26\end{array}$ & $\begin{array}{l}0.76(0 \cdot 13) \\
0.83(0.14) \\
+7 \cdot 2 \%(+1 \cdot 6,+12 \cdot 8)\end{array}$ & $\begin{array}{l}0.77(0.13) \\
0 \cdot 81(0 \cdot 14) \\
+4 \cdot 9 \%(-0.7,+10 \cdot 5)\end{array}$ \\
\hline $\begin{array}{l}\text { Visual narrowing } \\
\text { only }(0-3) \\
\geq 1\end{array}$ & $\begin{array}{l}0 \\
1\end{array}$ & $\begin{array}{r}540 \\
14\end{array}$ & $\begin{array}{l}0.77(0.13) \\
0.77(0 \cdot 18) \\
+0 \%(-9.5,+9 \cdot 5)\end{array}$ & $\begin{array}{l}0.77(0 \cdot 13) \\
0.76(0 \cdot 18) \\
-1 \cdot 3 \%(-10 \cdot 8,+8 \cdot 2)\end{array}$ \\
\hline $\begin{array}{l}\text { Ruler narrowing } \\
\text { only } \\
\leq 2 \mathrm{~mm}\end{array}$ & $\begin{array}{l}0 \\
1\end{array}$ & $\begin{array}{r}545 \\
18\end{array}$ & $\begin{array}{l}0.77(0 \cdot 12) \\
0.79(0 \cdot 19) \\
+2 \cdot 5 \%(-3 \cdot 3,+8 \cdot 3)\end{array}$ & $\begin{array}{l}0.77(0 \cdot 13) \\
0.78(0 \cdot 13) \\
+1 \cdot 3 \%(-4 \cdot 5,+7 \cdot 1)\end{array}$ \\
\hline $\begin{array}{l}\text { Digital image } \\
\text { Narrowing only } \\
\leq 3.6 \mathrm{~mm}\end{array}$ & $\begin{array}{l}0 \\
1\end{array}$ & $\begin{array}{r}539 \\
37\end{array}$ & $\begin{array}{l}0.77(0 \cdot 13) \\
0 \cdot 80(0 \cdot 12) \\
+3.8 \%(-0 \cdot 5,+8 \cdot 1)\end{array}$ & $\begin{array}{l}0.77(0 \cdot 1.3) \\
0 \cdot 79(0 \cdot 13) \\
+2 \cdot 5 \%(-1 \cdot 8,+6 \cdot 8)\end{array}$ \\
\hline
\end{tabular}

bone density of $+4 \cdot 9 \% \quad(-1 \cdot 1,+10 \cdot 9)$, FNBMD $+4 \cdot 9 \%(-0 \cdot 7,+10 \cdot 5)$. The ageadjusted results alone showed a more positive effect on BMD of all the narrowing measures, although in all analyses the BMD difference was higher in the osteophyte group. Additional adjustment for spinal osteophytes did not markedly effect the results although they generally increased the percentage increase in LSBMD.

The risk of knee $\mathrm{OA}$ in relation to bone density was also assessed. The top tertile of spine BMD had an adjusted odds ratio of $2 \cdot 13$ (95\% CI 1.15-3.93). For each standard deviation increase in LSBMD the odds for knee OA increased by $1 \cdot 82$.

\section{Discussion}

Our data show a small but significant increase in bone density in middle-aged women with OA defined on the basis of osteophytes of the hand, knee and lumbar spine. Bone density of the lumbar spine showed an adjusted mean increase ranging from $3 \cdot 0-9 \cdot 3 \%$ and for the $\mathrm{FN}$ the increase in BMD had a range between $1 \cdot 3-6 \cdot 3 \%$. The presence of osteophytes at the lumbar spine did not explain the increase in LSBMD as adjustment for the presence of osteophytes did not alter the estimated difference. We were unable to distinguish the effects of joint space loss and osteophyte formation in the knee on bone density.

The influence of facet joint OA on bone density is unclear, and it is possible that this could have affected our results, although the relevance and diagnosis of facet joint $\mathrm{OA}$ remains controversial.

Aortic calcification on lateral lumbar spine radiographs may also influence bone density results. In our middle-aged population aortic calcification was only present in five cases. There was no difference in mean spine BMD in those cases compared with the rest of the population.

The classification of OA for epidemiological studies remains a problem with no clear gold standard. ${ }^{17} 18$ The most accepted and reproducible method is probably the presence of radiographic OA using standard atlases, particularly that of $K \& \mathrm{~L}$ which depend on the presence of the osteophyte. ${ }^{11} 1319$ 
If bone density is inversely related to OA, it is possible that an increase in severity of OA might yield an increase in bone density. In our population there was little severe disease, only 14 cases, but in this group no difference was seen in LSBMD or FN BMD by grade of OA. This result was also confirmed in a preliminary report in an elderly population from the Framingham cohort in which no difference was found in BMD between grades of severity of OA. ${ }^{20}$

Response bias is unlikely to be a problem in this study given the good response rate of $78 \%$ and the fact that we did not use self report or symptoms as disease definition. The population was also broadly representative of the UK female population. ${ }^{9} 10$

It is well known that age, physical activity and obesity are related both to bone density and $\mathrm{OA}$ and were potential confounders. However, adjustment for these variables as well as less established factors, such as, cigarette smoking and HRT did not affect the results.

These data support the hypothesis that osteoporosis and OA are inversely related. The first studies found OA was associated with above average bone density, and that $\mathrm{OA}$ and OP rarely coexisted in the same patients. ${ }^{12}$ Dequeker also suggested that since they did not occur together there may be an inverse association of the two diseases. ${ }^{3} \mathrm{He}$ also proposed morphological differences within each disease, the lean osteoporotic and the fatter, more muscular OA subject. Most early work examined subjects with primary OA of the hip. ${ }^{12}$ Reid found no association with hand $\mathrm{OA}$ and bone mass measured with total body calcium. ${ }^{7}$ However, Pogrund found that in the hand, osteoporosis and OA coexisted in only $3-4 \%$ in a general population survey. ${ }^{5}$ Price found an increase in trabecular BMD in GOA subjects when adjusting for age, but when adjusting for skeletal size the difference disappeared. ${ }^{6}$ In a small study comparing patients with rheumatoid arthritis, psoriatic arthritis and osteoarthritis, and controls, Cooper found that 11 patients with isolated large joint OA had higher bone mass, while 19 with primary generalised OA did not. ${ }^{21}$ Data from the Tecumseh Community Health Study showed that women with hand OA had higher bone density, as measured by radiographic metacarpal index, but higher ratio of subsequent loss. ${ }^{22} \mathrm{~A}$ similar study from the Baltimore longitudinal study of ageing in males found a relationship between metacarpal index and hand $\mathrm{OA}$, which disappeared after adjustment for confounders. ${ }^{23}$

Our results were not able to distinguish the association between higher bone density with the presence of osteophytes (in the knee) and isolated joint space narrowing, whether measured by categorical grade, ruler or computer. The relative importance of joint space narrowing and osteophytes in the definition of OA of the knee is still unclear. It is well recognised that oestrogen deficiency has an important role in osteoporosis, and there is some evidence for the role of sex hormones in the aetiology of OA in females. Obesity is a major risk factor for OA, but the unequal influences on weightbearing sites, ${ }^{24}$ and a weak relationship in the hand joints suggest the association may be mediated, at least in part by metabolic or hormonal factors, as levels of oestrogens are considerably raised in obesity. An unconfirmed study has suggested that levels of free sex hormones may be higher in middleaged women with osteoarthritis. ${ }^{25}$ The epidemiology of GOA in females also suggests a role of female sex hormones, with often an acute onset around the menopause and a high female to male sex ratio. ${ }^{26}$ Animal studies have generally supported a role for an excess in oestrogens as being harmful. ${ }^{25} \operatorname{Radin}^{27}$ proposed that the structure of bone was different in the two diseases, with osteoporotic bone being 'softer' and OA bone being 'stiffer' and in the presence of repeated loading resulted in fractures in the former and cartilage damage in the latter.

Another possibility is that genetic effects are in some way responsible for the relationship. The genetics of OA are unclear and few studies have been performed although isolated families with a rare early form of the disease have been found to have minor abnormalities of collagen type II. ${ }^{28}$ More work has been performed in osteoporosis which suggests that as much as $80 \%$ of the variation in bone density can be explained by genetic factors. Twin studies have also suggested that the genetic differences can be explained on the basis of markers of bone formation (such as, osteocalcin) which appear to be regulated by the vitamin $\mathrm{D}$ receptor gene. ${ }^{29}$ Thus recent evidence points to a defect in the regulation of bone turnover rather than a structural collagen defect. Individuals may therefore be genetically predisposed to be 'bone formers', and these individuals have higher bone density, with less chance of osteoporotic fracture and a greater tendency to develop osteophytes and develop OA.

The clinical significance of a $5-7 \%$ increase in BMD in subjects with OA needs to be addressed. This amount is equivalent to reducing age-related bone loss by five years, which becomes important in later life when hip and vertebral fractures can double in incidence over this time frame. Although important data on osteoarthritis and subsequent fractures are lacking, extrapolation of our cross-sectional results would suggest that the risk of subsequent fractures may be halved in this group. Conversely, we found that women in the upper tertile of BMD had a two-fold increased risk of knee OA.

In conclusion we have found that in a population of middle-aged females bone density is higher in those with OA, as defined by the presence of osteophytes, compared with normal subjects. These results were not affected after adjustment for confounding variables including the presence of osteophytes in the lumbar spine. Although the mechanisms are unclear these data suggest that some females inherit a bone forming tendency which may confer a small protection against osteoporosis but increases the risk of osteoarthritis. 
We thank the staff at Chingford Hospital for their cooperation with this study, and the general practice and patients at Highams Park Medical Partnership. The study was partly funded by a grant from the Joint Research Board of $S$ Bartholomew's Hospital. We are also grateful to Jane Dacre for her help with the computerised image analysis measurements.

1 Foss M V L, Byers P D. Bone density, osteoarthritis of the hip and fracture of the upper end of the femur. Ann Rheum Dis 1972; 31: 259-64

2 Roh Y S, Dequeker J, Mulier J C. Bone mass in osteoarthritis measured in vivo by photon absorbtion. f Bone foint Surg 1974; 56: 587-91.

3 Dequeker J. The relationship between osteoporosis and osteoarthritis. Clin Rheum Dis 1985; 11: 271-96.

4 Cooper C, Cook P L, Osmond C, Fisher L, Cawley M I D. Osteoarthritis of the hip and osteoporosis of the proximal femur. Ann Rheum Dis 1991; 50: 540-2.

5 Pogrund $H$, Rutenberg $M$, Makin $M$, Robin G $C$ Steinberg R, Bloom R. Osteoarthritis of the hand and osteoporosis. Clin Orthop 1986; 203: 239-43.

6 Price T, Hesp R, Mitchell R. Bone density in generalised osteoarthritis. F Rheumatol 1987; 14(3):560-2.

7 Reid D M, Kennedy N S J, Smith M A, Tothill P, Nuki G. Bone Mass in nodal primary generalised osteoarthrosis. Ann Rheum Dis $1984 ; 43: 240-2$.

8 Knight I. The heights and weights of adults in Great Britain. OPCS: HMSO, 1984

9 Wald N, Nicolaides-Bouman A. UK Smoking statistics, 2nd ed. London: Oxford University Press, 1991.

10 Spector T D, Brennan P, Harris P, Studd J W W, Silman A J. Does estrogen replacement therapy protect Silman A J. Does estrogen replacement

11 Kellgren $\mathrm{J} \mathrm{H}$. The epidemiology of chronic rheumatism atlas of standard radiographs, vol 2. Oxford, Blackwell atlas of standar

12 Spector T D, Dacre J E, Harris P A, Huskisson E C. The radiological progression of OA: an 11 year follow up of the knee. Ann Rheum Dis 1992; 51: 1107-10.

13 Spector T D, Cooper C, Cushnaghan J, Hart D J, Dieppe P A. A radiographic atlas of knee osteoarthritis. London: Springer-Verlag, 1992.

14 Dacre J E, Huskisson E C. The automatic assessment of knee radiographs in osteoarthritis using digital image analysis. Arthritis Rheum 1987; 30: 1214-225.
15 Spector T D, Hart D J. How serious is knee osteoarthritis? Ann Rheum Dis 1992; 51: 1105-6.

16 Orwell E S, Oviatt S K, Mann T. The impact of osteophytic and vascular calcification on vertebral mineral density measurements in men. 7 Clin Endocrinol Metab 1990; 70: 1202-7.

17 McAlindon T, Dieppe P. Osteoarthritis: definition and criteria. Ann Rheum Dis 1989; 48: 531-2.

18 Spector T D, Cooper C. The definition of osteoarthritis in epidemiologic studies: whither Kellgren and Lawrence. Osteoarthritis and cartilage 1993 (in press).

19 Spector T D, Hart D J, Byrne J, Harris P A, Dacre J E, Doyle D V. A definition of osteoarthritis of the knee for epidemiologic studies. Ann Rheum Dis 1993; 52: 790-4.

20 Hannan M T, Zhang Y, Anderson J J, Felson D T. Bone mineral density and knee osteoarthritis in elderly men and women: The Framingham Study. Arthritis Rheum 1992; 35: $\mathrm{S} 1(\mathrm{~S} 40)$

21 Cooper C, Poll V, McLaren M, Daunt S O N, Cawley M I D. Alterations in appendicular skeletal mass in patients with rheumatoid, psoriatic, and osteoin patients with rheumatoid, psoriatic,

22 Sowers $M$, Zobel D, Weissfeld L, Hawthorne V M Carman W. Progression of osteoarthritis of the hand and metacarpal bone loss. Arthritis Rheum 1991; 34(1): 36-42.

23 metacarpal bone loss. Arthritis Rheum 1991; 34(1): 36-42. Wigley F M, Tobin J D. Factors associated with Wigley F M, Tobin J D. Factors associated with 134: 1121-7.

24 Spector T D. The fat on the Joint: Osteoarthritis and obesity. F Rheumatol 1990; 17: 3 .

25 Spector T D, Perry L A, Jubb R W. Endogenous sex steroid levels in women with generalised osteoarthritis. Clinical Rheumatol 1991; 10: 316-19.

26 Spector T D, Campion G C. Generalized osteoarthritis is a hormonally mediated disease. Ann Rheum Dis 1989; 48 523-7.

27 Radin E L Paul I L, Rose R M. The role of mechanical factors in pathogenesis of primary osteoarthritis. Lancet 1972;1: 519-22.

28 Alla-Kokko L Baldwin C T, Moskowitz R W, Prockup D J A single base mutation in the type II procollagen gene Col $2 \mathrm{Al}$ ) as a cause of primary osteoart with mild chondrodysplasia. Proc Natl Acad Sci (USA) 1990; 87: 6565-8.

29 Morrison N A, Yeoman R, Kelly P J, Eisman J A Osteocalcin levels define functionally different alleles of the human Vitamin D receptor. Proc Natl Acad Sci 1992; 89: $6665-9$. 